\title{
Active paraplegics are protected against exercise-induced oxidative damage through the induction of antioxidant enzymes
}

\author{
M Inglés ${ }^{1,5}$, P Serra-Añó ${ }^{1,5}, \mathrm{~J}_{\text {Gambini }}{ }^{2}, \mathrm{~F}$ Abu-Sharif ${ }^{3}, \mathrm{M}$ Dromant $^{2}$, R Garcia-Valles ${ }^{2}, \mathrm{H}$ Pareja-Galeano ${ }^{4}$, \\ C Garcia-Lucerga ${ }^{1}$ and MC Gomez-Cabrera ${ }^{2}$
}

\begin{abstract}
Study design: Experimental study.
Objectives: Exercise improves functional capacity in spinal cord injury (SCI). However, exhaustive exercise, especially when sporadic, is linked to the production of reactive oxygen species that may have a detrimental effect on $\mathrm{SCl}$. We aimed to study the effect of a single bout of exhaustive exercise on systemic oxidative stress parameters and on the expression of antioxidant enzymes in individuals with paraplegia.
\end{abstract}

Setting: The study was conducted in the Physical Therapy department and the Physical Education and Sports department of the University of Valencia.

Methods: Sixteen paraplegic subjects were submitted to a graded exercise test (GET) until volitional exhaustion. They were divided into active or non-active groups. Blood samples were drawn immediately, 1 and $2 \mathrm{~h}$ after the GET. We determined plasma malondialdehyde (MDA) and protein carbonylation as markers of oxidative damage. Antioxidant gene expression (catalase and glutathione peroxidase-GPx) was determined in peripheral blood mononuclear cells.

Results: We found a significant increase in plasma MDA and protein carbonyls immediately after the GET $(P<0.05)$. This increment correlated significantly with the lactate levels. Active paraplegics showed lower levels of exercise-induced oxidative damage $(P<0.05)$ and higher exercise-induced catalase $(P<0.01)$ and GPx $(P<0.05)$ gene expression after the GET.

Conclusions: These results suggest that exercise training may be useful in $\mathrm{SCl}$ patients to develop systemic antioxidant defenses that may protect them against exercise-induced oxidative damage.

Spinal Cord (2016) 54, 830-837; doi:10.1038/sc.2016.5; published online 16 February 2016

\section{INTRODUCTION}

The beneficial health effects of regular moderate physical exercise are known for a long time. ${ }^{1}$ In fact, exercise has been traditionally considered as an important part of the primary and secondary prevention of several chronic diseases such as cardiovascular disease, diabetes, cancer, hypertension, obesity, depression and osteoporosis, ${ }^{2}$ and it has even been proposed as a drug among the elderly. ${ }^{3}$

Furthermore, physical activity and exercise are important for optimizing mobility and reducing sedentary lifestyles among individuals with mobility impairments, such as those suffering from paraplegia after a spinal cord injury (SCI). In this regard, numerous studies have focused on the beneficial effects of various exercise-based rehabilitation interventions and concluded that exercise is effective in improving both physical capacity and muscular strength, and even promoting neural plasticity in individuals with SCI, thus improving their functional capacity. ${ }^{4,5}$ However, all these beneficial effects may be lost when exercise is exhaustive (especially when sporadic). Exhaustive exercise can cause structural damage to muscle cells or inflammatory reactions within the muscles-for instance, as evidenced by an increase in the plasma activity of cytosolic enzymes and sarcolemma and Z-line disruption. ${ }^{6}$

Exhaustive exercise-induced free radical production is involved in this muscle damage, as evidenced by altered muscle glutathione levels and the protein, lipid and DNA oxidation found after intense muscular contractile activity. ${ }^{7-9}$ In this regard, our research group demonstrated that a single bout of exhaustive exercise caused oxidative stress only when exhaustive. ${ }^{10}$ We found a linear correlation between a well-known marker of oxidative stress, oxidized to reduced glutathione (GSSG to GSH ratio) and lactate-to-pyruvate ratio. Such changes in indicators of cellular redox imbalance occurred only when exercise was exhaustive, independently of the absolute intensity of exercise in patients suffering from chronic obstructive pulmonary disease. $^{11}$

On the other hand, there is growing evidence that the continued presence of low concentrations of reactive oxygen species (ROS) is able to induce the antioxidant system, thus increasing the expression

${ }^{1}$ Department of Physiotherapy, Faculty of Physiotherapy, University of Valencia, Valencia, Spain; ${ }^{2}$ Department of Physiology, Faculty of Medicine, University of Valencia; Investigación Hospital Clínico Universitario/INCLIVA, Valencia, Spain; ${ }^{3}$ Hospital Universitario y Politécnico La Fe, Valencia, Spain and ${ }^{4}$ European University of Madrid and Research Institute of Hospital 12 de Octubre ('i+12'), Madrid, Spain

5These two authors contributed equally to this work.

Correspondence: Dr MC Gómez-Cabrera, Department of Physiology, Faculty of Medicine, University of Valencia, Avenue Blasco Ibañez, 15, Valencia E46010, Spain.

E-mail: carmen.gomez@uv.es

Received 2 June 2015; revised 12 November 2015; accepted 13 December 2015; published online 16 February 2016 
Table 1 General characteristics of the participants

\begin{tabular}{|c|c|c|c|c|c|c|c|c|c|c|c|}
\hline Weight (kg) & Height (m) & $B M I\left(\mathrm{~kg} \mathrm{~m}^{-2}\right)$ & Age (years) & Gender & Time since injury (months) & $N L I$ & Etiology & MVPA & $\mathrm{VO}_{2}$ peak & Time to exhaustion (s) & $W$ max. (W) \\
\hline \multicolumn{12}{|c|}{ Non-active group } \\
\hline 87 & 1.72 & 25.3 & 68 & Male & 93 & $\mathrm{~T} 4-5$ & Tumoral ${ }^{\mathrm{a}}$ & 59 & 17.2 & 240 & 60 \\
\hline 70 & 1.76 & 19.9 & 56 & Male & 405 & T5 & Traumatic & 45 & 15.3 & 284 & 60 \\
\hline 43 & 1.54 & 14.0 & 33 & Female & 64 & $\mathrm{~T} 4$ & Traumatic & 51 & 12.0 & 108 & 30 \\
\hline 57 & 1.74 & 16.4 & 37 & Male & 225 & T3 & Traumatic & 19 & 28.8 & 690 & 100 \\
\hline 85 & 1.72 & 24.7 & 48 & Male & 447 & T6-7 & Tumoral $^{\mathrm{b}}$ & 43 & 23.7 & 495 & 90 \\
\hline 82 & 1.90 & 21.6 & 54 & Male & 292 & $\mathrm{T7}$ & Traumatic & 22 & 19.3 & 590 & 90 \\
\hline 63 & 1.65 & 19.1 & 37 & Male & 94 & T7 & Traumatic & 149 & 25.7 & 370 & 75 \\
\hline \multicolumn{12}{|l|}{ Active group } \\
\hline 60 & 1.74 & 17.2 & 34 & Male & 70 & T6 & Traumatic & 729 & 49.7 & 857 & 100 \\
\hline 75 & 1.73 & 21.7 & 57 & Male & 321 & $\mathrm{~T} 1$ & Traumatic & 201 & 12.7 & 120 & 30 \\
\hline 69 & 1.81 & 19.1 & 27 & Male & 94 & $\mathrm{T7}$ & Traumatic & 266 & 20.0 & 390 & 75 \\
\hline 65 & 1.56 & 20.8 & 44 & Female & 189 & $\mathrm{~T} 11$ & Traumatic & 202 & 23.5 & 200 & 45 \\
\hline 85 & 1.82 & 23.3 & 31 & Male & 105 & $\mathrm{~T} 11$ & Traumatic & 202 & 13.0 & 680 & 100 \\
\hline 75 & 1.71 & 21.9 & 30 & Male & 17 & $\mathrm{~T} 11$ & Traumatic & 236 & 22.2 & 440 & 75 \\
\hline 125 & 1.87 & 33.4 & 39 & Male & 108 & $\mathrm{~T} 4$ & Traumatic & 262 & 15.0 & 510 & 90 \\
\hline 77 & 1.77 & 21.7 & 45 & Male & 50 & $\mathrm{~T} 4$ & Traumatic & 598 & 13.4 & 257 & 60 \\
\hline 70 & 1.92 & 18.2 & 34 & Male & 203 & $\mathrm{T7}$ & Traumatic & 265 & 28.0 & 668 & 100 \\
\hline
\end{tabular}

Abbreviations: BMI, body mass index; NLI, neurological level of injury; MVPA, self-reported moderate-to-vigorous physical activity; T, thoracic.

aBenign spinal cord astrocytoma, T4-T5 level with neurological stability.

benign spinal cord ependymoma, T6-T7 level with neurological stability.

of antioxidant genes such as catalase, glutathione peroxidase (GPx) and superoxide dismutase. ${ }^{12}$ Exhaustive exercise leads to an excess in ROS production that causes molecular and even cellular damage. However, ROS produced during moderate exercise have a physiological rolethat is, they behave as signals to modulate adaptations of muscle to exercise. Paramount among these adaptations is the activation of antioxidant genes. In this scenario, regular moderate exercise-induced free radicals may be seen as beneficial, as they act as signals to enhance defenses, so that trained individuals are more protected against exhaustive-induced oxidative damage. ${ }^{13}$ In fact, we proposed that moderate exercise itself can be considered as an antioxidant because it increases the expression of classical antioxidant enzymes. ${ }^{13}$

Oxidative stress, particularly lipid peroxidation cascades and associated inflammation, has been described to occur after the acute episode of the SCI. ${ }^{14}$ Indeed, antioxidant administration has been proposed as an effective therapeutic intervention in SCI patients. ${ }^{15}$ However, no one has studied beyond the acute phase of SCI the relationship between exercise and oxidative stress in individuals suffering from SCI.

Thus, the aim of this manuscript was to study the effect of a single bout of exhaustive exercise on systemic oxidative stress parameters and on the expression of antioxidant enzymes in individuals with paraplegia. Our results underline the importance of determining the optimal intensity, frequency and duration of exercise in rehabilitation interventions among individuals with paraplegia and open up the possibility of giving antioxidant substances to the non-active SCI individuals to minimize the damaging effects of intense physical exercise.

\section{METHODS}

\section{Participants}

Sixteen paraplegic subjects (14 males and 2 females) were included in the study. All participants were in a stable clinical condition (that is, the event occurred at least 2 years before the beginning of the study), presented a level of injury between T3 and T11 and all used a wheelchair as their primary means of mobility. The American Spinal Injury Association Impairment Scale (AIS) was used to assess the level and completeness of SCI, and the examination was conducted by a medical specialist. All of them presented a score between A and B. Subjects were divided into active or non-active groups on the basis of an accelerometry threshold of $180 \mathrm{~min}$ per week of moderate-to-vigorous physical activity (MVPA) as described below. ${ }^{16-18}$ The general characteristics and the clinical and injury-related parameters of the subjects are shown in Table 1. No differences in baseline physical and physiological characteristics were found between groups (see Table 1).

None of the participants showed symptoms of cardiorespiratory disease or other pathological conditions such as pressure sores or motor disabilities of their upper limbs that could affect their performance during exercise. Subjects taking antioxidants were excluded from the study. To control the intensity of shoulder pain during daily activities in the participants, the Wheelchair Users Shoulder Pain Index (WUSPI) was administered to each participant following the instruction previously described by Curtis et al. ${ }^{19}$ (data not shown).

All subjects were informed verbally and in writing about the nature of this study, including all potential risks. Written informed consent was obtained prior to participation. All procedures were conducted in accordance with the principles of the World Medical Association's Declaration of Helsinki, and the protocols were approved by the Ethics Committee of the University of Valencia.

\section{Measurements of physical activity by accelerometry}

An accelerometer Actigraph model GT3X (Actigraph, Pensacola, FL, USA) was used to collect the accelerations achieved over 7 days. This device was previously validated for this population $(r=0.86$; root mean square error $=$ 2.23). ${ }^{20}$ The monitor was worn during night and day, and it did not need to be removed, except during water activities. Data were saved to a hard disk for subsequent analyses. A specific ad hoc function was written using Matlab R2010a (Mathworks Inc, Natick, MA, USA) to reduce and remove incorrect data and to perform the calculations of the variables. To accurately report physical activity outcomes, data that registered 1200 consecutive ' 0 ' counts were defined as non-wear time and were consequently removed..$^{21}$ Subjects who did not wear the accelerometer for at least $9 \mathrm{~h}$ over 4 days were not included in the study.

On the basis of the accelerations collected, the intensity levels of physical activity were subdivided into light, moderate-to-vigorous and sedentary behavior, depending on the metabolic equivalents of task values. ${ }^{22}$ Therefore, we extracted the number of minutes per week the participants spent performing MVPA (values greater than 3 metabolic equivalents of task), and 
they were separated into two groups-those who performed more than 180 min per week of MVPA were included in the active group and those who performed less than 180 min per week were included in the non-active group. ${ }^{16-18}$

\section{Graded exercise test procedures}

Participants reported to the laboratory in the morning after eating a light breakfast or a light meal. Following 15 min rest, a pre-exercise blood sample was taken from an antecubital forearm vein.

Each subject was assessed for aerobic fitness by determining their $\mathrm{VO}_{2}$ peak. To perform the graded exercise test (GET), an arm-ergometer was used (Monark 881E, Stockholm, Sweden). This ergometer was firmly anchored to the table, and its pedals were placed in a position in which, in a static position, the elbow of each participant was at 90 degrees of flexion. Participants were sitting in their own wheelchair with its brakes set. The participants started the protocol with a warm-up, 10 min pedaling with their arms with a power of 0 watts. Immediately, the GET started. They were asked to maintain the same pedal cadence (60 r.p.m.) during the test. Participants started with a initial workload of 30 watts, and the clinical researchers increased the power 15 watts every 2 min until volitional exhaustion. ${ }^{23}$ The $\mathrm{VO}_{2}$ peak was taken as the highest $\mathrm{VO}_{2}$ value and was stated as being achieved by three of the following four end point criteria: (i) blood lactate concentration of $7-8 \mathrm{~mm}$, (ii) respiratory quotient $>1.1$, (iii) plateau of oxygen consumption despite increasing workload and (iv) achievement of $90 \%$ of age-adjusted maximal heart rate.

Expired fractions of oxygen and carbon dioxide were analyzed by the COSMED K4b2 portable metabolic measurement system (K4b2, Cosmed, Rome, Italy). During the final $10 \mathrm{~s}$ of each power increment of the GET, participants estimated their overall rate of perceived exertion using the Borg 6-20 RPE Scale. ${ }^{24}$

Heart rate was measured continuously by a heart rate monitor (Polar, Sportstester, PE3000, Kempele, Finland) fitted to the chest at the V5 position and averaged over 5-s intervals.

\section{Sampling}

Capillary blood lactate was determined at the beginning and at the end of the test by using the Lactate proTM, Netherlands.

Blood samples were drawn from the antecubital vein just before the beginning of the $\mathrm{VO}_{2}$ peak test, immediately, 1 and $2 \mathrm{~h}$ after the test. They were collected in tubes containing ethylenediaminetetraacetic acid as anticoagulant, to obtain plasma (centrifugation at $1500 \mathrm{~g}$ for $15 \mathrm{~min}$ at room temperature), or in VACUTAINER CPT (Cell Preparation Tube) (BD, Franklin Lakes, NJ, USA) containing sodium heparin as anti-coagulant, to obtain peripheral blood mononuclear cells (PBMCs). VACUTAINER tubes were centrifuged at $3000 \mathrm{~g}$ for $15 \mathrm{~min}$ at room temperature within half an hour of blood collection. We then collected the white ring containing mononuclear cells. Plasma and mononuclear cells were frozen at $-80^{\circ} \mathrm{C}$ until analysis.

Laboratory personnel were all blinded to the sample's identity.

\section{Plasma lipid peroxidation}

Plasma lipid peroxidation was determined as malondialdehyde (MDA) formed from lipoperoxides, which was detected using high-performance liquid chromatography as an MDA-thiobarbituric acid adduct following a method described previously. ${ }^{25}$ This method is based on the hydrolysis of lipoperoxides in plasma and subsequent formation of an adduct between thiobarbituric acid and MDA (thiobarbituric acid-MDA ${ }_{2}$ ). This adduct was detected using high-performance liquid chromatography in reverse phase and quantified at $532 \mathrm{~nm}$. The chromatographic technique was performed under isocratic conditions, the mobile phase being a mixture of monopotassium phosphate $50 \mathrm{~mm}(\mathrm{pH} 6.8)$ and acetonitrile (70:30).

\section{Protein carbonylation measured using western blotting}

The carbonyl groups in the protein side chains were derivatized to 2,4-dinitrophenylhydrazone by reacting with 2,4-dinitrophenylhydrazine so that they could be detected by western blotting using specific antibodies, as previously described. ${ }^{26}$ Oxidative modification of total proteins was assessed by immunoblot detection of plasma protein carbonyl groups using the OxyBlot
Protein Oxidation Detection kit in accordance with the manufacturer's instructions (Millipore, Billerica, MA, USA). The procedure to quantify total protein carbonyls using the OxyBlot kit was densitometry of the Oxyblot and Ponceau staining followed by finding the ratio between the total density in the Oxyblot and the Ponceau.

\section{RNA isolation by TRIzol and mRNA gene expression by real-time} polymerase chain reaction (RT-PCR)

Catalase and GPx mRNA expression was determined by real-time PCR with glyceraldehyde-3P-dehydrogenase (GAPDH) as the endogenous control, according to previously published results. ${ }^{27,28}$ For this purpose, total RNA was isolated from mononuclear cells by extraction with TRIzol Reagent (Invitrogen, Carlsbad, CA, USA), according to the manufacturer's instructions. RNA was quantified by measuring the absorbance at $260 \mathrm{~nm}$. The purity of the RNA preparations was assessed by the 260/280 ratio.

cDNA was synthesized from $1 \mu \mathrm{g}$ total RNA using an reverse transcriptase system kit of Applied Biosystems (Foster City, CA, USA; High-Capacity cDNA Reverse Transcription Kits). The reaction was incubated as recommended by the manufacturer for $10 \mathrm{~min}$ at $25^{\circ} \mathrm{C}$, followed by $120 \mathrm{~min}$ at $37^{\circ} \mathrm{C}$, then for 5 min at $85^{\circ} \mathrm{C}$, and finally cooled to $4^{\circ} \mathrm{C}$ to collect the cDNA and then stored at $-20^{\circ} \mathrm{C}$ prior to the real-time PCR assay.

The quantitative PCR was performed using the detection system $7900 \mathrm{HT}$ Fast Real-Time PCR System (Applied Biosystems) with Maxima SYBR Green/ROX qPCR Master Mix (2X) (Fermentas, Foster City, CA, USA). Target and control were run in separate wells.

Specific primers used, sense and antisense for each gene, respectively, were as follows: catalase, 5'-ACG TTG GAT GGA GAA GTG CGG AGA TTC AAC-3' and $5^{\prime}$-ACG TTG GAT GTT CAC ATA GAA TGC CCG CAC-3'; GPx $5^{\prime}$-GCC CAG TCG GTG TAT GCC TTC TC- $3^{\prime}$ and $5^{\prime}$-AGG GAC GCC ACA TTC TCG ATA AGT A-3'; GAPDH, 5'-CCT GGA GAA ACC TGC CAA GTA TG- $3^{\prime}$ and $5^{\prime}$-GGT CCT CAG TGT AGC CCA AGA TG- $3^{\prime}$. Target and control cDNAs were run in triplicate using the following procedure: $10 \mathrm{~min}$ at $95^{\circ} \mathrm{C}$ and then 40 cycles of denaturation $95^{\circ} \mathrm{C}$ for $15 \mathrm{~s}$ and annealing and extension at $62^{\circ} \mathrm{C}$ for $1 \mathrm{~min}$ per cycle.

The threshold cycle (CT) was determined and then the relative gene expression was expressed as follows: Relative amount $=2-\Delta(\Delta \mathrm{CT})$, where $\Delta \mathrm{CT}=\mathrm{CT}$ target $-\mathrm{CT}$ Housekeeping control, and $\Delta(\Delta \mathrm{CT})=\Delta \mathrm{CT}$ studied group $-\Delta$ CT baseline.

\section{Statistical analysis}

Statistical analysis was performed using PASW v.21 (SPSS Inc., Chicago, IL, USA). All dependent variables complied with the assumption of normality (Shapiro-Wilks normality test). Standard statistical methods were used to obtain the mean and the standard deviation or standard error of the mean.

For exploring the influence of the GET on plasma oxidative damage (dependent variables: MDA and protein carbonyl levels) and on gene expression (dependent variables: GPx and catalase), a one-way repeated measures multivariate analysis of variance was applied considering the time as the within-subject factor. In these analyses of variance, planned contrast was performed to compare each moment after the GET-namely, immediately after the GET (after), $1 \mathrm{~h}$ after the GET ( $1 \mathrm{~h}$ after) and $2 \mathrm{~h}$ after the GET ( $2 \mathrm{~h}$ after) -with the sample collected before starting the GET.

The relationship between changes registered (between the time before and after the GET) in all dependent variables both in variables representing oxidative damage and those representing gene expressions was analyzed using Pearson's correlation test.

To explore the influence of being or not active (that is, pertaining to the active or not active groups) over the dependent variables, an analysis of covariance was conducted. The dependent variables were MDA, protein carbonylation, GPx and catalase mRNA levels and the covariable was the $\mathrm{VO}_{2}$ peak achieved during the GET. The time was used as a within-subject factor. The assumption of homogeneity of regression slopes and the independence of the covariate and treatment effect were tested and assumed.

This analysis of covariance was repeated to test the effect of being or not active over the changes (before and after the GET) in all the dependent variables.

The level of statistical significance was set at $P=0.05$. 


\section{RESULTS}

Plasma oxidative damage increases in paraplegic subjects after one bout of exhaustive exercise

Volitional exhaustion was confirmed by several physiological parameters in all the subjects (see Methods section). ${ }^{29}$ The Borg-RPE Scale, which has been proved to be effective in controlling moderate and vigorous intensities throughout a $20 \mathrm{~min}$ handcycling exercise session for SCI participants, ${ }^{30}$ averaged a value of 20 , indicating self-reported exhaustion.

We determined plasma MDA and protein carbonyl levels as biomarkers of systemic oxidative damage and observed a main effect of the GET on these two biomarkers along the times in which the blood sampling was obtained: $F(3,45)=5.16, P<0.01, \eta 2 p=0.26$ for $\mathrm{MDA}$ and $\mathrm{F}(3,45)=6.17, \quad P<0.01, \eta 2 \mathrm{p}=0.29$ for protein carbonylation.

As shown in Figure 1a, we found a $24.50 \%$ increase in subject's MDA levels immediately after finishing the GET when compared with their basal values $(P<0.05)$. However, $1 \mathrm{~h}$ later, MDA levels returned to basal values $(P>0.05)$. Regarding plasma protein carbonylation (Figure 1b), we found a significant increase in protein oxidation immediately $(34.12 \% ; P<0.05)$ and $1 \mathrm{~h}$ after the completion of the GET $(22.75 \%$; $P<0.05)$, when compared with the basal extraction. Protein carbonyl levels $2 \mathrm{~h}$ after the exercise completion were not statistically different from basal $(P>0.05)$.

Figure 1c shows that there is a correlation between MDA and protein carbonyl increments $(r=0.71, P<0.01)$ when we compared
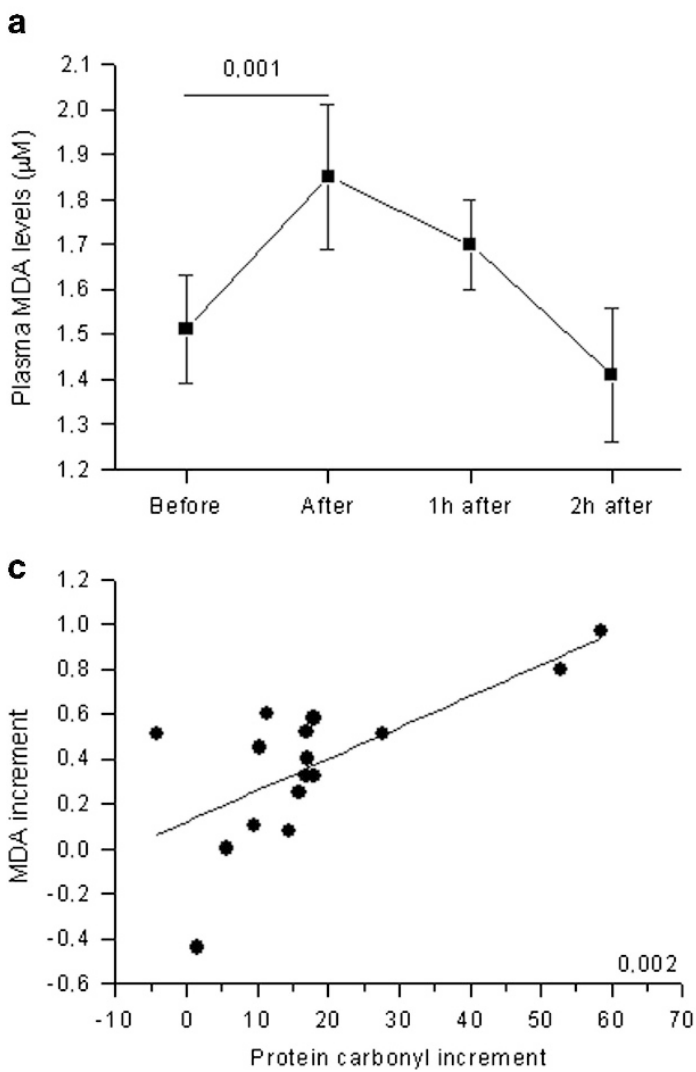

Figure 1 Oxidative damage in paraplegic subjects after exhaustive exercise. Oxidative damage in paraplegic subjects ( $n=16$ ) submitted to a GET and analyzed at four different times: before, immediately, 1 or $2 \mathrm{~h}$ after the test completion. (a) Plasma MDA levels. (b) Densitometric analysis (a.u.: arbitrary units) for plasma protein carbonyl levels. For both (a) and (b), black squares represent the mean and error bars represent the s.e. Values above the horizontal line indicate the $P$ value between conditions. (c) Pearson's correlation test between MDA and protein carbonyl level increments (immediately after vs before. $P=0.002$ ). (d) Pearson's correlation test between the increment in plasma MDA and lactate levels (immediately after vs before. $P=0.048$ ). For both (c) and (d), values inside the graph indicate the $P$ value of the correlation. the samples immediately after the GET vs before. Figure 1d shows increments $(r=0.50, P<0.05)$. However, we do not find a significant association between plasma protein carbonyls and lactate increments (data not shown).

Antioxidant gene expression does not change in paraplegic subjects after one bout of exhaustive exercise

We determined GPx and catalase mRNA gene expression in PBMCs as indicators of the induction of systemic antioxidant defense, before and $2 \mathrm{~h}$ after the completion of the GET. Figures $2 \mathrm{a}$ and $\mathrm{b}$ show that, although there is a tendency $(P=0.182$ for GPx and $P=0.084$ for catalase), we did not observe a statistically significant increase in the antioxidant gene expression $2 \mathrm{~h}$ after the GET completion. Figure $2 \mathrm{c}$ shows a significant positive correlation between catalase and GPx mRNA expression increments, which supports the tendency found in Figures $2 \mathrm{a}$ and $\mathrm{b}(\mathrm{r}=0.60, P<0.05)$. Moreover, we found a significant negative correlation between GPx mRNA expression and the increment in plasma MDA levels $2 \mathrm{~h}$ after the GET $(r=-0.673, P<0.01)$.

Active paraplegics show lower exercise-induced oxidative damage and higher exercise-induced antioxidant mRNA expression than the non-active ones

It has been previously shown that exercise training induces the antioxidant defense not only in the skeletal muscle but also in blood cells, which endows trained individuals with a protection against the

b

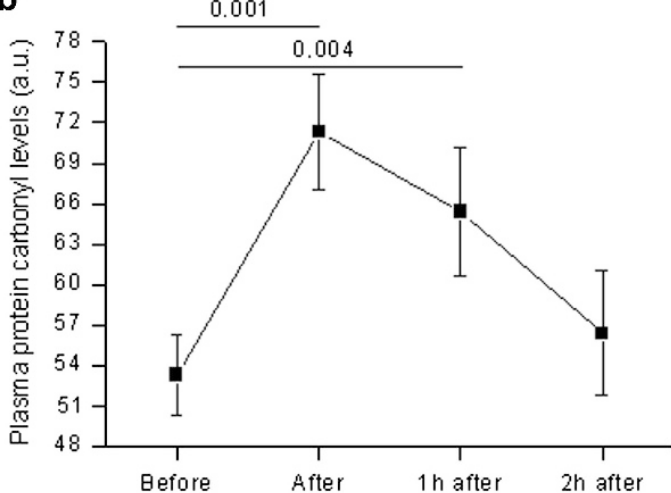

d

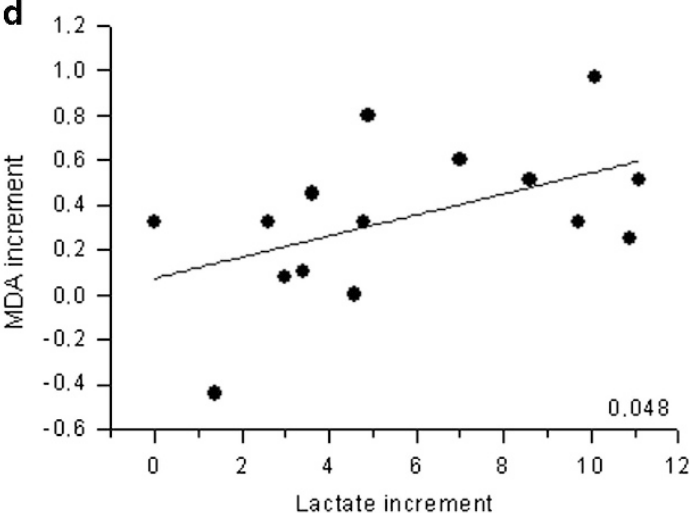
a statistically significant correlation between MDA and lactate 

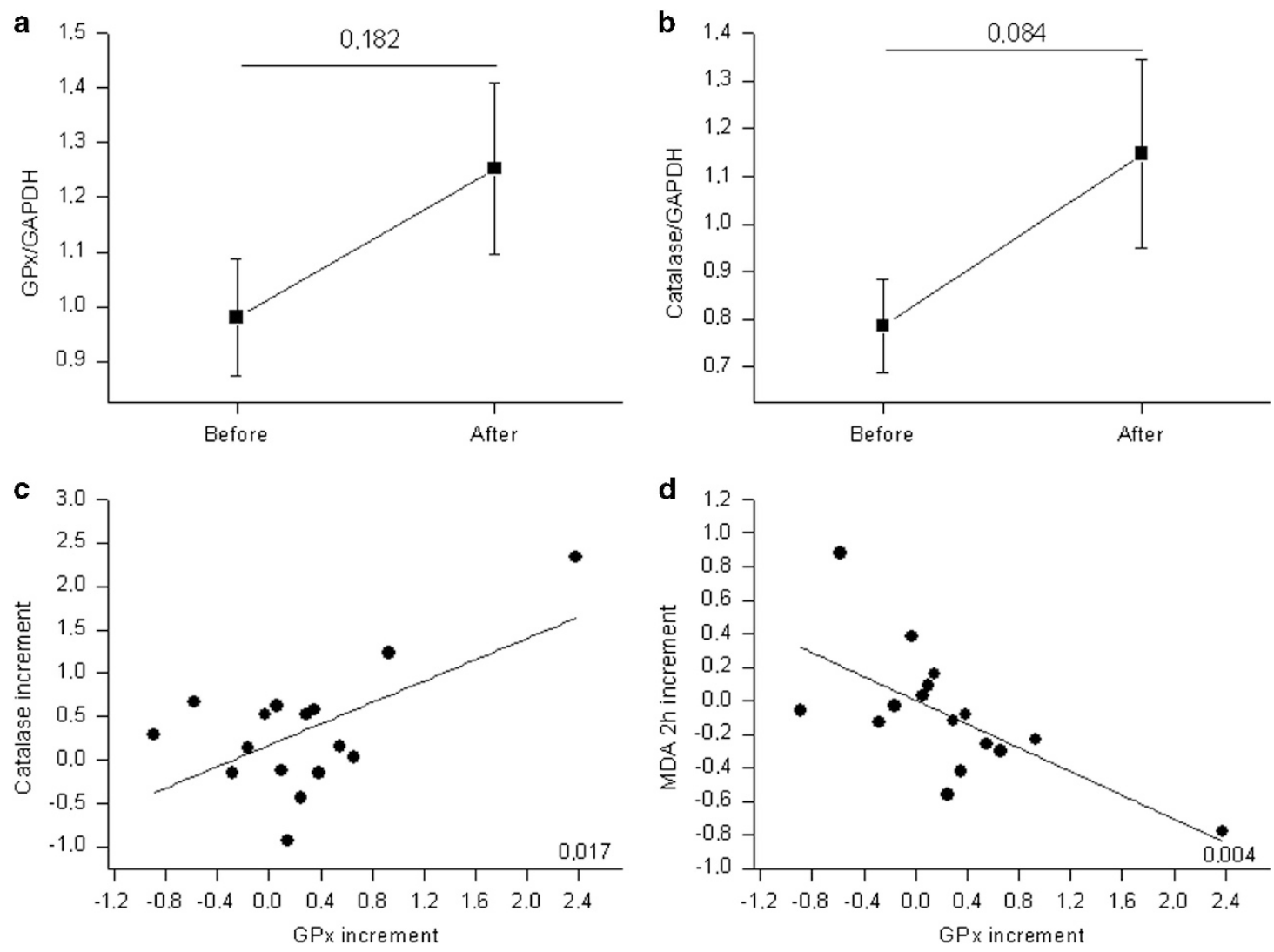

Figure 2 Antioxidant gene expression in paraplegic subjects after exhaustive exercise. Antioxidant gene expression in paraplegic subjects submitted to a GET $(n=16)$. GPx (a) and catalase (b) mRNA expressions were determined before and $2 \mathrm{~h}$ after the test completion. For both (a) and (b), the black squares represent the mean and error bars represent the s.e. Values above the horizontal line indicate the $P$ value between conditions. (c) Pearson's correlation test between GPx and catalase mRNA expression increment. (d) Pearson's correlation test between the increment in GPx mRNA expression and the increment in plasma MDA levels. For both (c) and (d), values inside the graph indicate the $P$ value of the correlation.

exercise-induced oxidative damage. ${ }^{31,32}$ Thus, we divided our subjects into two groups (active and non-active) on the basis of their physical activity levels (MVPA).

When we compared the oxidative damage before and after the GET between groups taking into consideration the $\mathrm{VO}_{2}$ peak as a covariable, we found that both non-active and active individuals showed significantly higher levels of oxidative damage markers (that is, MDA and protein carbonyls) immediately after the GET, comparing with basal levels (Figure 3). Indeed, plasma MDA levels immediately after the GET were $17.20 \%$ higher in the active individuals $(P<0.05)$ and $27.91 \%$ higher in the non-active ones $(P<0.01)$, comparing with basal levels (Figure 3a). We also found a $29.02 \%$ increase in protein carbonyl levels in the active group $(P<0.05)$ and a $39.81 \%$ increase in the non-active one $(P<0.05)$ after the exercise (Figure $3 \mathrm{~b})$. In the same way and as Figure 4 indicates, the active group shows a higher catalase $(13.91 \% ; P<0.01)$ and GPx $(62.6 \% ; P<0.05)$ mRNA levels in PBMCs after the GET than the non-active one. There were no significant differences in the increment between groups $(P>0.05)$. No differences in basal mRNA antioxidant gene expression were found among groups.

\section{DISCUSSION}

Exhaustive exercise is associated with the overproduction of ROS, decreased ability of the antioxidant system to counteract such damage and an increase in oxidative stress biomarkers in able-bodied subjects. 9,33
In the present study, exhaustive exercise caused a transient increase in lipid peroxides and protein carbonyls measured in plasma, which was followed by a fall in both parameters to baseline levels $2 \mathrm{~h}$ after exercise cessation. Similar decreases in plasma lipid peroxides have been reported previously in human studies following exercise but with a different time course ${ }^{34,35}$ (15 min after exercise cessation), which could be attributed to the differences in the type of exercise performed. Our observation of a bi-phasic change in plasma lipid peroxide concentration in response to a bout of exercise might be one mechanism by which exercise exerts, for instance, atheroprotective effects. ${ }^{36}$ Exercise-induced increase in lipid peroxidation and protein carbonylation in plasma of healthy subjects has been demonstrated in several studies. ${ }^{33,37}$ To the best of our knowledge, our results indicate, for the first time, that subjects with SCI performing strenuous exercise have an increase in peripheral oxidative stress markers. Unlike healthy able-bodied subjects, paraplegic individuals become fatigued at low-intensity external workload. In the study by Sastre et al., using healthy subjects, exercise duration until exhaustion averaged $12 \mathrm{~min}$. In a similar study, but in chronic obstructive pulmonary disease patients, Heunks et al. ${ }^{38}$ found that the exercise duration until exhaustion lasted only $6.4 \pm 0.6 \mathrm{~min}$. In our case, the average duration of the exercise protocol until exhaustion was $7.4 \pm 3$ min. Besides the differences in the exercise protocols between the referenced studies and ours (leg vs arm exercise), the increments in the plasma MDA levels in all the studies were similar and comparable with those found in our study. We also found a linear correlation between MDA and 

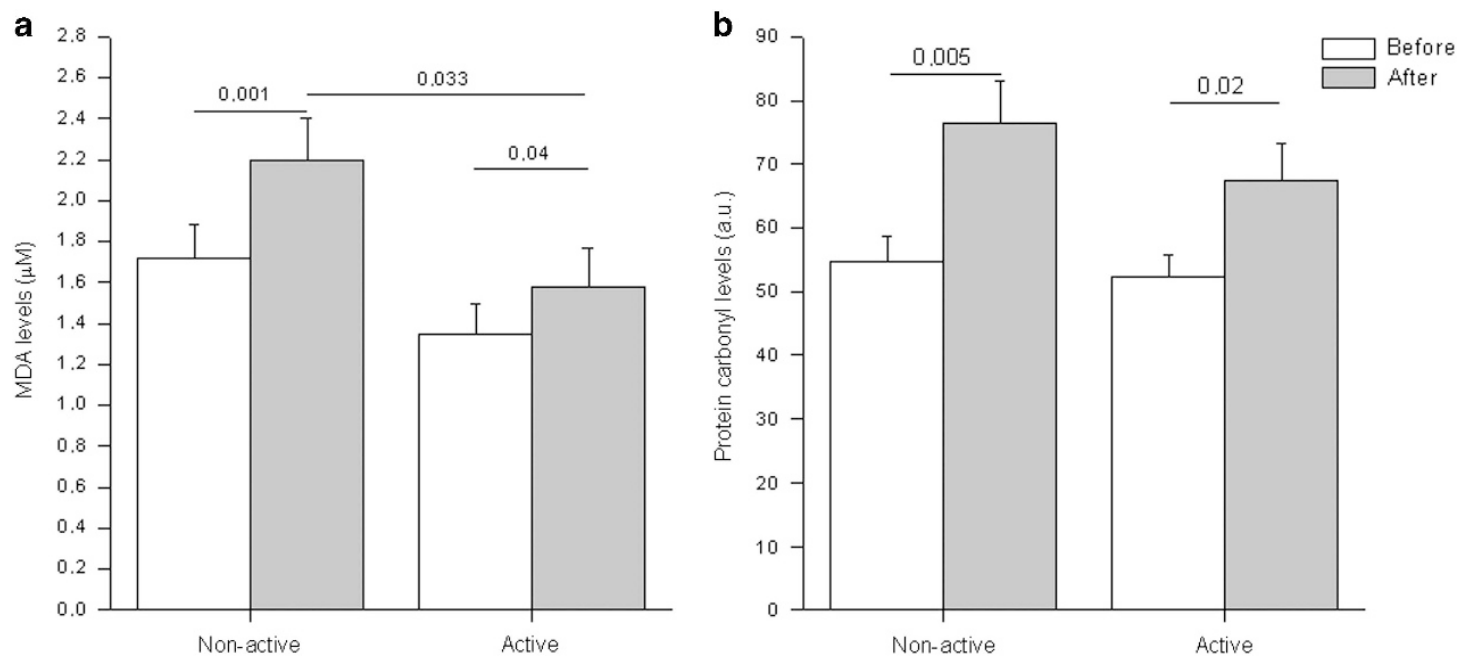

Figure 3 Plasma MDA and protein carbonyl levels in non-active and active paraplegic subjects after exhaustive exercise. Plasma MDA (a) and protein carbonyl (b) levels in non-active $(n=7)$ and active $(n=9)$ paraplegic subjects submitted to a GET, before and immediately after the test completion. Columns represent the mean and error bars represent the s.e. Values above the horizontal line indicate the $P$ value between conditions.

a

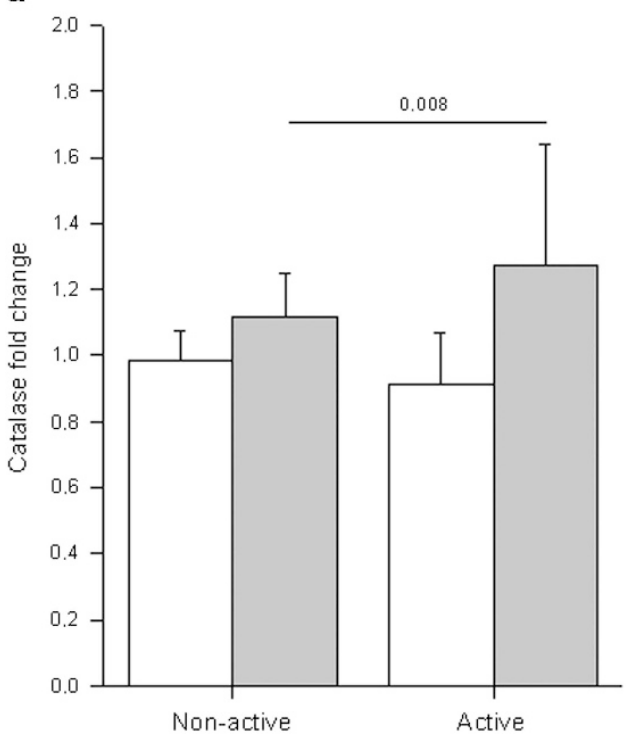

b

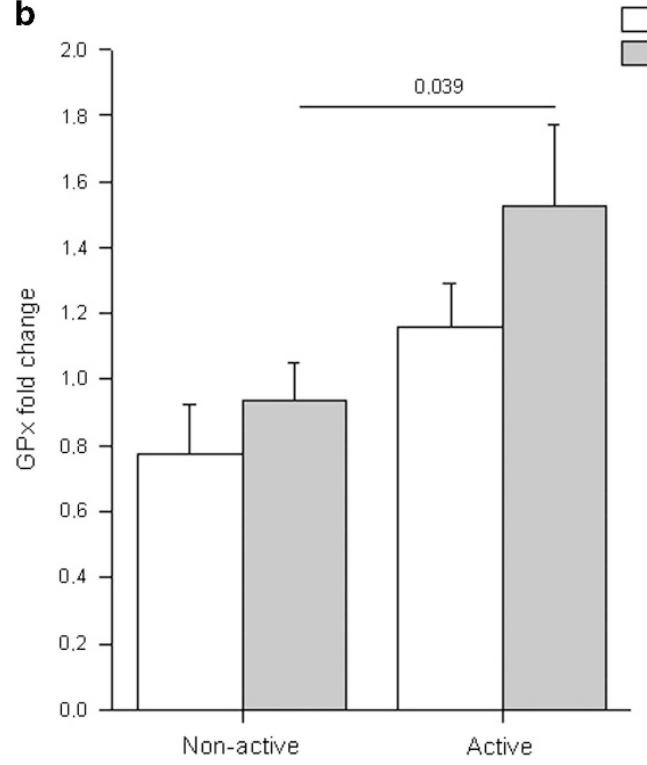

Figure 4 Antioxidant gene expression in non-active and active paraplegic subjects after exhaustive exercise. Catalase (a) and GPx (b) mRNA expression in non-active $(n=7)$ and active $(n=9)$ paraplegic subjects submitted to a GET, before and $2 \mathrm{~h}$ after the test completion. Columns represent the mean and error bars represent the s.e. Values above the horizontal line indicate the $P$ value between conditions.

lactate increments when we compared the samples immediately after the GET vs before. Blood lactate levels were 5-6 times higher, and MDA levels were 1.24 times higher after exercise than before it. These data support the hypothesis that in subjects with SCI, it is the exhaustion, and not the absolute intensity or duration of the exercise, what determines the potential damage of such exercise. In this regard, our research group found in 1992 a linear correlation between GSSG-to-GSH and lactate-to-pyruvate ratios in human blood after exhaustive exercise. Three years later, a correlation between lactate levels and the activity of xanthine oxidase (a free radical-generating enzyme) was reported after an exercise protocol. ${ }^{39}$

Some studies have shown that the formation of ROS immediately after injury may contribute to the pathogenesis of SCI. ${ }^{40,41}$ However, the impact of oxidative stress in SCI beyond the acute phase has not been so far elucidated. Our data suggest that administration of antioxidants might be of relevance in paraplegic patients submitted to sporadic exhaustive exercise sessions (once or twice a week). ${ }^{42}$ However, controlled studies are needed to accurately determine the effects of this type of intervention on oxidative stress biomarkers.

The training level of the individuals is an important aspect to take into account to understand the variable effects of exhaustive exercise in terms of oxidation. There are several evidences supporting this assumption. When we determined the subjects' training level by using accelerometry, we did not find differences in the $\mathrm{VO}_{2}$ peak between the non-active and the active groups. This contradictory result argues against the usefulness of $\mathrm{VO}_{2}$ peak to classify the level of activity in individuals with paraplegia, especially those having differences in their NLI. Robertson et al. ${ }^{31}$ examined the antioxidant status of trained runners and sedentary individuals and found that the antioxidant capacity was enhanced in the runners and that the fittest athletes do 
not show an increase in oxidative stress parameters after exhaustive exercise. Thus, our subjects were divided into active or non-active on the basis of an accelerometry threshold of $180 \mathrm{~min}$ per week of MVPA. This criterion was based on the recommendation of previous studies in which the health benefits of performing MVPA were explored. ${ }^{16-18}$

We found that both non-active and active individuals showed significantly higher levels of oxidative damage markers (that is, MDA and protein carbonyl levels) immediately after the GET, comparing with basal levels (see Figure 3). However, that increment was higher in the non-active group than in the active one. Indeed, plasma MDA levels immediately after the GET were significantly lower in active individuals when compared with the non-active ones. This may be due to the induction of the antioxidant enzymes due to exercise training in different tissues. ${ }^{13}$

We found that one bout of exhaustive exercise tends to increase the expression of the antioxidant genes, GPx $(P=0.182)$ and catalase $(P=0.084)$, in PBMCs after the completion of the GET. In ablebodied subjects, it has been reported that a maximal test on an electromagnetic reduction cycloergometer ${ }^{43}$ and a single 25-min diving session ${ }^{44}$ are able to induce GPx and catalase activities in lymphocytes $2-3 \mathrm{~h}$ after the exercise. Interestingly, we found that only the active group achieved a statistically significant increase in both genes after the GET and that they also displayed lower oxidative damage to lipids when compared with the non-active group, which suggests that regular training protects against acute exercise-induced oxidative damage by inducing antioxidant genes. Jenkins and co-workers ${ }^{32}$ reported that highly trained subjects had significantly greater muscle catalase and superoxide dismutase activities than those subjects in a low-moderate fit group. This adaptation in the expression of antioxidant enzymes is dependent on the exercise-induced increase in ROS because administration of antioxidants hampers this induction. ${ }^{12,45}$ This response is systemic and includes enhancement of antioxidant systems and the reduction in oxidative damage due to changes in redox homeostasis. ${ }^{46}$ We consider that the lack of differences in the expression of the antioxidant enzymes in PBMCs in basal conditions among the groups (active vs non-active) may be explained because of their training level. As shown in Table 1, our active subjects cannot be considered highly trained subjects.

Our study has some limitations. The sample was small, and the inter-individual variability was high. This may be the reason why we did not find, for instance, statistically significant differences in the antioxidant gene expression before and after the GET (see Figure 2). The other drawback of our study is that we could not divide the individuals by age nor gender, as the sample recruitment in SCI is obviously limited.

The main finding reported here is that active paraplegics are more protected against exercise-induced oxidative damage than non-active ones, through the induction of antioxidant enzyme mRNA levels. Thus, long-term moderate-based physical activity is very important in regulating oxidative stress in SCI. Increasing $\mathrm{VO}_{2 \text { peak }}$ appeared to be not as important as moderate physical activity to develop systemic antioxidant defenses and lower exercise-induced oxidative damage. More studies are needed to clarify aspects such as exercise type, duration or intensity.

\section{DATA ARCHIVING}

There were no data to deposit.

\section{CONFLICT OF INTEREST}

The authors declare no conflict of interest.

\section{ACKNOWLEDGEMENTS}

This work was supported by grants SAF2013-44663-R from the Spanish Ministry of Education and Science (MEC), ISCIII2012-RED-43-029 from the 'Red Tematica de investigacion cooperativa en envejecimiento y fragilidad' (RETICEF), PROMETEO2014/056 from 'Conselleria d'Educació, Cultura i Esport de la Generalitat Valenciana', RS2012-609 Intramural Grant from INCLIVA and EU Funded CM1001 and FRAILOMIC-HEALTH.2012.2.1.1-2. The study has been co-financed by FEDER funds from the European Union.

1 Vina J, Sanchis-Gomar F, Martinez-Bello V, Gomez-Cabrera MC. Exercise acts as a drug; the pharmacological benefits of exercise. Br J Pharmacol 2012; 167: 1-12.

2 Warburton DE, Nicol CW, Bredin SS. Health benefits of physical activity: the evidence. CMAJ 2006; 174: 801-809.

3 Vina J, Borras C, Sanchis-Gomar F, Martinez-Bello VE, Olaso-Gonzalez G, Gambini J et al. Pharmacological properties of physical exercise in the elderly. Curr Pharm Des 2014; 20: 3019-3029.

4 Edgerton VR, Roy RR. Activity-dependent plasticity of spinal locomotion: implications for sensory processing. Exerc Sport Sci Rev 2009; 37: 171-178.

5 Hicks AL, Martin Ginis KA, Pelletier CA, Ditor DS, Foulon B, Wolfe DL. The effects of exercise training on physical capacity, strength, body composition and functional performance among adults with spinal cord injury: a systematic review. Spinal Cord 2011; 49: 1103-1127.

6 Armstrong RB, Ogilvie RW, Schwane JA. Eccentric exercise-induced injury to rat skeletal muscle. J Appl Physiol Respir Environ Exerc Physiol 1983; 54: 80-93.

7 Gomez-Cabrera MC, Borras C, Pallardo FV, Sastre J, Ji LL, Vina J. Decreasing xanthine oxidase-mediated oxidative stress prevents useful cellular adaptations to exercise in rats. J Physiol 2005; 567 (Pt 1): 113-120.

8 Radak Z, Pucsok J, Mecseki S, Csont T, Ferdinandy P. Muscle soreness-induced reduction in force generation is accompanied by increased nitric oxide content and DNA damage in human skeletal muscle. Free Radic Biol Med 1999; 26: 1059-1063.

9 Sanchis-Gomar F, Pareja-Galeano H, Gomez-Cabrera MC, Candel J, Lippi G, Salvagno GL et al. Allopurinol prevents cardiac and skeletal muscle damage in professional soccer players. Scand J Med Sci Sports 2015; 25: e110-e115.

10 Sastre J, Asensi M, Gasco E, Pallardo FV, Ferrero JA, Furukawa T et al. Exhaustive physical exercise causes oxidation of glutathione status in blood: prevention by antioxidant administration. Am J Physiol 1992; 263 (5 Pt 2): R992-R995.

11 Vina J, Servera E, Asensi M, Sastre J, Pallardo FV, Ferrero JA et al. Exercise causes blood glutathione oxidation in chronic obstructive pulmonary disease: prevention by 02 therapy. J Appl Physiol (1985) 1996; 81: 2198-2202.

12 Gomez-Cabrera MC, Domenech E, Romagnoli M, Arduini A, Borras C, Pallardo FV et al. Oral administration of vitamin $\mathrm{C}$ decreases muscle mitochondrial biogenesis and hampers training-induced adaptations in endurance performance. Am J Clin Nutr 2008; 87: 142-149.

13 Gomez-Cabrera MC, Domenech E, Vina J. Moderate exercise is an antioxidant: upregulation of antioxidant genes by training. Free Radic Biol Med 2008; 44: $126-131$.

14 Kamencic H, Griebel RW, Lyon AW, Paterson PG, Juurlink BH. Promoting glutathione synthesis after spinal cord trauma decreases secondary damage and promotes retention of function. FASEB J 2001; 15: 243-250.

15 Jia Z, Zhu H, Li J, Wang X, Misra H, Li Y. Oxidative stress in spinal cord injury and antioxidant-based intervention. Spinal Cord 2012; 50: 264-274.

16 Jacobs PL, Nash MS. Exercise recommendations for individuals with spinal cord injury. Sports Med 2004; 34: 727-751.

17 Myers J, Nieman D. ACSM's Resources for Clinical Exercise Physiology, 2nd edn Wolters Luwer/Lippincott Williams \& Wilkins: Baltimore, MD, USA. 2010.

18 Myslinski MJ. Evidence-based exercise prescription for individuals with spinal cord injury. J Neurol Phys Ther 2005; 29: 104-106.

19 Curtis KA, Drysdale GA, Lanza RD, Kolber M, Vitolo RS, West R. Shoulder pain in wheelchair users with tetraplegia and paraplegia. Arch Phys Med Rehabil 1999; 80: 453-457.

20 Garcia-Masso X, Serra-Ano P, Garcia-Raffi LM, Sanchez-Perez EA, Lopez-Pascual J, Gonzalez LM. Validation of the use of Actigraph GT3X accelerometers to estimate energy expenditure in full time manual wheelchair users with spinal cord injury. Spinal Cord 2013; 51: 898-903.

21 Esliger DW, Copeland JL, Barnes JD, Tremblay MS. Standardizing and optimizing the use of accelerometer data for free-living physical activity monitoring. J Phys Act Health 2005; 3: 366-383.

22 Freedson PS, Melanson E, Sirard J. Calibration of the Computer Science and Applications, Inc. accelerometer. Med Sci Sports Exerc 1998; 30: 777-781.

23 Al-Rahamneh HQ, Eston RG. Prediction of peak oxygen consumption from the ratings of perceived exertion during a graded exercise test and ramp exercise test in able-bodied participants and paraplegic persons. Arch Phys Med Rehabil 2011; 92: 277-283.

24 Borg G. Borg's Perceived Exertion and Pain Scales. Human Kinetics: Champaign, IL, US: 1998.

25 Wong SH, Knight JA, Hopfer SM, Zaharia O, Leach CN Jr., Sunderman FW Jr. Lipoperoxides in plasma as measured by liquid-chromatographic separation of malondialdehyde-thiobarbituric acid adduct. Clin Chem 1987; 33 (2 Pt 1): 214-220. 
26 Ingles M, Gambini J, Carnicero JA, Garcia-Garcia FJ, Rodriguez-Manas L, Olaso-Gonzalez $\mathrm{G}$ et al. Oxidative stress is related to frailty, not to age or sex, in a geriatric population: lipid and protein oxidation as biomarkers of frailty. J Am Geriatr Soc 2014; 62: 1324-1328.

27 Borras C, Gambini J, Gomez-Cabrera MC, Sastre J, Pallardo FV, Mann GE et al. 17beta-oestradiol up-regulates longevity-related, antioxidant enzyme expression via the ERK1 and ERK2[MAPK]/NFkappaB cascade. Aging Cell 2005; 4: 113-118.

28 Ingles M, Gambini J, Miguel MG, Bonet-Costa V, Abdelaziz KM, El Alami M et al. PTEN mediates the antioxidant effect of resveratrol at nutritionally relevant concentrations. Biomed Res Int 2014; 2014: 580852.

29 Howley ET, Bassett DR Jr., Welch HG. Criteria for maximal oxygen uptake: review and commentary. Med Sci Sports Exerc 1995; 27: 1292-1301.

30 Goosey-Tolfrey V, Lenton J, Goddard J, Oldfield V, Tolfrey K, Eston R. Regulating intensity using perceived exertion in spinal cord-injured participants. Med Sci Sports Exerc 2010; 42: 608-613.

31 Robertson JD, Maughan RJ, Duthie GG, Morrice PC. Increased blood antioxidant systems of runners in response to training load. Clin Sci (Lond) 1991; 80: 611-618.

32 Jenkins RR, Friedland $\mathrm{R}$, Howald $\mathrm{H}$. The relationship of oxygen uptake to superoxide dismutase and catalase activity in human skeletal muscle. Int J Sports Med 1984; 5: 11-14.

33 Gomez-Cabrera MC, Pallardo FV, Sastre J, Vina J, Garcia-del-Moral L. Allopurinol and markers of muscle damage among participants in the Tour de France. Jama 2003; 289 . 2503-2504.

34 Turner JE, Bosch JA, Drayson MT, Aldred S. Assessment of oxidative stress in lymphocytes with exercise. J Appl Physiol (1985) 2011; 111: 206-211.

35 Kretzschmar M, Muller D, Hubscher J, Marin E, Klinger W. Influence of aging, training and acute physical exercise on plasma glutathione and lipid peroxides in man. Int $J$ Sports Med 1991; 12: 218-222.
36 Ginsburg GS, Agil A, O'Toole M, Rimm E, Douglas PS, Rifai N. Effects of a single bout of ultraendurance exercise on lipid levels and susceptibility of lipids to peroxidation in triathletes. Jama 1996; 276: 221-225.

37 Powers SK, Jackson MJ. Exercise-induced oxidative stress: cellular mechanisms and impact on muscle force production. Physiol Rev 2008; 88: 1243-1276.

38 Heunks LM, Vina J, van Herwaarden CL, Folgering HT, Gimeno A, Dekhuijzen PN. Xanthine oxidase is involved in exercise-induced oxidative stress in chronic obstructive pulmonary disease. Am J Physiol 1999; 277 (6 Pt 2): R1697-R1704.

39 Radak Z, Asano K, Inoue M, Kizaki T, Oh-Ishi S, Suzuki K et al. Superoxide dismutase derivative reduces oxidative damage in skeletal muscle of rats during exhaustive exercise. J App/ Physiol 1995; 79: 129-135.

40 Taoka Y, Naruo M, Koyanagi E, Urakado M, Inoue M. Superoxide radicals play important roles in the pathogenesis of spinal cord injury. Paraplegia 1995; 33: 450-453.

41 Liu D, Liu J, Sun D, Wen J. The time course of hydroxyl radical formation following spinal cord injury: the possible role of the iron-catalyzed Haber-Weiss reaction. J Neurotrauma 2004; 21: 805-816.

42 Lee IM, Sesso HD, Oguma Y, Paffenbarger RS Jr. The 'weekend warrior' and risk of mortality. Am J Epidemiol 2004; 160: 636-641.

43 Tauler P, Aguilo A, Gimeno I, Guix P, Tur JA, Pons A. Different effects of exercise tests on the antioxidant enzyme activities in lymphocytes and neutrophils. J Nutr Biochem 2004; 15: 479-484.

44 Ferrer MD, Sureda A, Batle JM, Tauler P, Tur JA, Pons A. Scuba diving enhances endogenous antioxidant defenses in lymphocytes and neutrophils. Free Radic Res 2007; 41: 274-281.

45 Ristow M, Zarse K, Oberbach A, Kloting N, Birringer M, Kiehntopf M et al. Antioxidants prevent health-promoting effects of physical exercise in humans. Proc Natl Acad Sci USA 2009; 106: 8665-8670.

46 Radak Z, Chung HY, Goto S. Systemic adaptation to oxidative challenge induced by regular exercise. Free Radic Biol Med 2008; 44: 153-159. 